\title{
The 2nd Symposium on Multiscale, Multiphase, Multiphysics and Turbulent Flow Simulations
}

Cite as: AIP Conference Proceedings 1978, 320001 (2018); https://doi.org/10.1063/1.5043932

Published Online: 10 July 2018

Serdar Çelebi, and Mine Çağlar

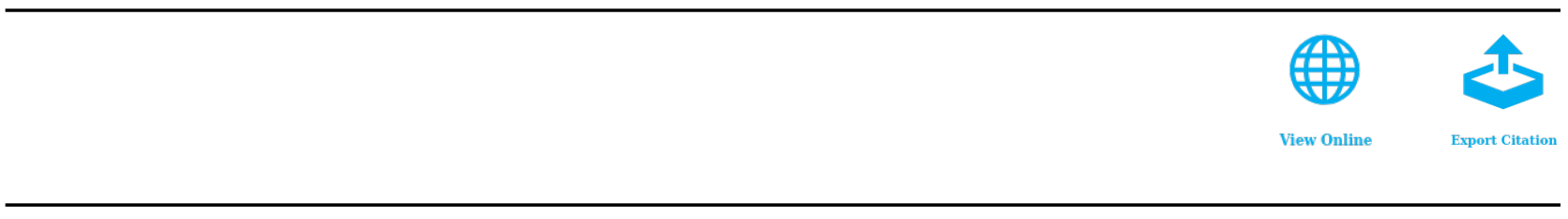

\section{Conference Proceedings}

Get $30 \%$ off all print proceedings!

\section{Enter Promotion Code PDF30 at checkout}

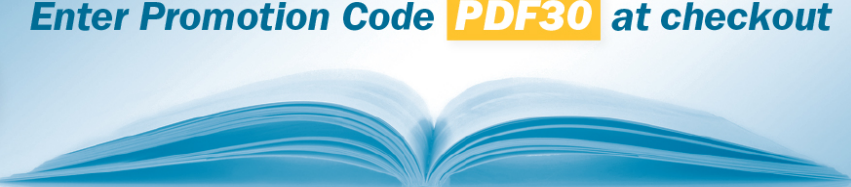




\title{
The 2nd Symposium on Multiscale, Multiphase, Multiphysics and Turbulent Flow Simulations
}

\author{
Serdar Çelebi ${ }^{1, a)}$ and Mine Çağlar ${ }^{2, b)}$ \\ ${ }^{I}$ Informatics Institute, Istanbul Technical University, Turkey \\ ${ }^{2}$ Koc University, Istanbul, Turkey \\ a)mscelebi@itu.edu.tr \\ b)mcaglar@ku.edu.tr
}

The aim of this Symposium is to cover research areas related to multiscale, multiphase, multiphysics and turbulent flows and create a collaborative environment for the leading scientists and research groups to share their experiences in fundamental and applied aspects. The core objective is to have a thorough understanding of these fields by giving an in-depth analysis of the simulation and modeling approaches to demonstrate the recent novel methods and the theories.

Emphasis will not be only on the theoretical aspects but also on the implementation of numerical methods and algorithms used in large scale simulations of multiscale, multiphase, multiphysics and turbulent flows. All application areas ranging from fluid dynamics and biomedical flows to environmental sciences are welcome.

\section{Serdar Çelebi}

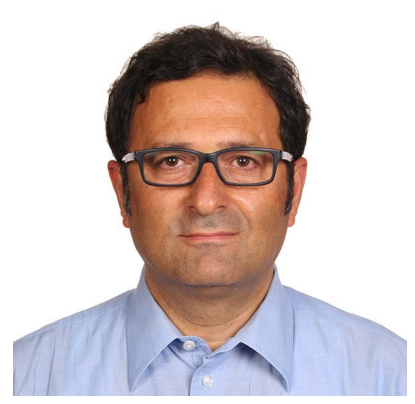

Istanbul Technical University

http://web.itu.edu.tr/ mscelebi/

\section{EDUCATION}

Texas A\&M University Ph.D. June, 1997 Computational Hydrodynamics College Station, Texas

Michigan University P.D. (N.A.) Jan., 1995 Computational Hydrodynamics Ann Arbor, Michigan

Istanbul Technical University M.Sc. Mar., 1990 Hydrodynamics Istanbul, Turkey

Istanbul Technical University B.Sc. May, 1987 Naval Architecture and Ocean Eng. Istanbul, Turkey

\section{RESEARCH INTERESTS}

Computational Fluid Dynamics, multi-phase flows, multi-physics simulations, biomechanics, Turbulence, bio-flows, multi-scale medical mechanics, parallel numerical algorithms, computational linear algebra.

\section{EXPERIENCE}

Professor, Istanbul Technical University, Informatics Institute, 2004 - Present, Associate Prof., Istanbul Technical University, Naval Arch. and Ocean Eng., 1998 - 2004, Assistant Prof., Istanbul Technical University, Naval Arch. and Ocean Eng., Jan. 1998 - Dec. 1998, Research Assistant, Texas A\&M University, Civil Engineering, Aug. 1995 - Dec. 1997, Research Assistant, University of Michigan, Naval Arch. and Ocean Eng., Oct. 1994 - May. 1995, Research Assistant, Istanbul Technical University, Naval Arch. and Ocean Eng., Jun.1988-May 1992. 


\section{Mine Çağlar}

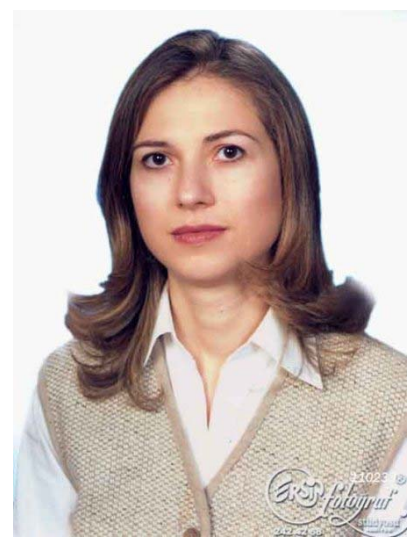

Koç University

http://home.ku.edu.tr/ mcaglar

\section{EDUCATION}

Princeton University Ph.D. June, 1997 Statistics \& Operations Research Princeton, NJ Bilkent University M.Sc. Mar., 1991 Industrial Engineering Ankara, Turkey Middle East Tech. Univ. B.Sc. May, 1989 Industrial Engineering Ankara, Turkey

\section{RESEARCH INTERESTS}

Probability theory and stochastic processes; in particular, stochastic flows, mathematics of finance, branching processes, telecommunication networks.

\section{EXPERIENCE}

Associate Professor, Koç University, College of Sciences, 2006-Present

Visiting Scholar, Columbia University, Department of Mathematics, 2014 Fall

Assistant Professor, Koç University, College of Sciences, 1999-2006

Research Scientist, Bellcore, Network Design \& Traffic Research Group, 1997-1998 